\title{
Professorandos-COM-GEOGEBRA: EXPERIÊNCIAS NA FORMAÇÃo DE PROFESSORES DE MATEMÁTICA
}

\author{
TEACHERS APPRENTICE-WITH-GEOGEBRA: EXPERIENCES IN MATHEMATICS TEACHERS \\ FORMATION
}

MAESTROS APRENDICES-CON-GEOGEBRA: EXPERIENCIAS EN LA FORMACIÓN DE PROFESORES DE MATEMÁTICAS

\author{
Márcio Nascimento da \\ Silva \\ (iD) 9 \\ Mestre em Matemática (UFC) \\ Atuação profissional: Professor na \\ Universidade Estadual Vale do \\ Acaraú (UVA) \\ Discente do Programa de Pós- \\ Graduação em Educação da \\ Universidade Federal de Pelotas \\ (PPGE/UFPel) \\ marcio@matematicauva.org
}

\section{Maristani Polidori \\ Zamperetti

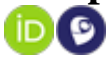

Doutora em Educação (UFPel)

Professora na Universidade

Federal de Pelotas (UFPel)

Docente do Programa de Pós-

Graduação em Educação da

Universidade Federal de Pelotas

(PPGE/UFPel)

maristaniz@hotmail.com

\begin{abstract}
Resumo
Este texto surge de reflexões acerca do uso de Tecnologias Digitais (TD) na formação de professores de Matemática e objetiva verificar como os licenciandos podem construir o conhecimento na presença do software GeoGebra. Partindo de indícios de pouco espaço para as TD nas licenciaturas, apresentamos três situações nas quais os professorandos utilizaram o GeoGebra em diferentes disciplinas do curso. Percebeu-se que na presença de smartphones e do GeoGebra, os estudantes reorganizaram a forma de compreensão dos assuntos, produzindo conhecimentos qualitativamente diferentes, com o uso das TD ocorrendo sob duas vertentes: o aprendizado do conteúdo matemático e a utilização para o ensino. Empregamos o termo professorandos-com-GeoGebra para o coletivo composto por humanos e tecnologias que se constitui na formação inicial. Concluímos que há necessidade de uma melhor sintonia entre formação e potencialidades das TD, sendo importante rever, em partes, as concepções dos formadores e dos cursos de licenciatura em Matemática.

Palavras-chave: Formação de professores. Pesquisa-ensino. Reorganização do pensamento. Smartphone. Tecnologias Digitais.
\end{abstract}

Recebido em: 12 de março de 2021. Aprovado em: 14 de maio de 2021.

Como citar esse artigo (ABNT):

SILVA, Márcio Nascimento da; ZAMPERETTI, Maristani Polidori. Professorandos-com-GeoGebra: experiências na formação de professores de Matemática. Revista Prática Docente, v. 6, n. 2, e028, 2021. http://doi.org/10.23926/RPD.2021.v6.n2.e028.id1058 


\section{Abstract}

This text arises from reflections about the use of Digital Technologies (DT) in the formation of Mathematics teachers and aims to verify how the undergraduate students can build knowledge in the presence of the GeoGebra software. Starting from indications of little space for DT in undergraduate courses, we present three situations in which future teachers used GeoGebra in different subjects of the course. It was noticed that in the presence of smartphones and GeoGebra, students reorganized the way of understanding the subjects, producing qualitatively different knowledge, with the use of DT occurring under two aspects: the learning of mathematical content and the use for teaching. We use the term teachers apprentice-withGeoGebra for the collective composed of humans and technologies that are constituted in the initial formation. We conclude that there is a need for a better harmony between formation and the potential of DT, and it is important to review, in part, the conceptions of university teachers and mathematics degree courses.

Keywords: Digital Technologies. Reorganization of thought. Research-teaching. Smartphone. Teacher formation.

\section{Resumen}

Este texto surge de reflexiones sobre el uso de las Tecnologías Digitales (TD) en la formación de profesores de Matemáticas y tiene como objetivo verificar cómo los estudiantes de pregrado pueden construir conocimiento en presencia del software GeoGebra. Partiendo de indicios de poco espacio para TD en los cursos de pregrado, presentamos tres situaciones en las que los maestros aprendices utilizaron GeoGebra en diferentes asignaturas del curso. Se notó que ante la presencia de smartphones y GeoGebra, los estudiantes reorganizaron la forma de entender las asignaturas, produciendo conocimientos cualitativamente diferentes, con el uso de TD ocurriendo bajo dos vertientes: el aprendizaje de contenidos matemáticos y el uso para la enseñanza. Usamos el término maestros aprendices-conGeoGebra para el colectivo compuesto por humanos y tecnologías que se constituyen en la formación inicial. Concluimos que existe la necesidad de una mejor alineación entre la formación y el potencial de la TD, y es importante revisar, en parte, las concepciones de formadores y carreras de matemáticas.

Palabras Clave: Formación de profesores. Investigacióndocencia. Reorganización del pensamiento. Smartphone. Tecnologías digitales. 


\section{O pouco espaÇo para as TeCnologias digitais na Formação inicial de PROFESSORES DE MATEMÁTICA}

Como vem sendo a formação dos professores de Matemática no Brasil no que se refere ao uso e compreensão do papel das Tecnologias Digitais? Neste texto procuramos abordar a referida questão focando no software GeoGebra. Nos últimos anos este software se tornou uma das principais ferramentas para professores de Matemática e estudantes, porém, assim como as tecnologias digitais em geral, ainda é subutilizado como recurso pedagógico nos cursos de formação (CASTRO, 2015; LIMA et al., 2018).

Com o intuito de verificar como os professores em formação podem construir o conhecimento matemático na presença desta TD específica, o GeoGebra, começamos por contextualizar a formação de professores de Matemática do ponto de vista da legislação.

A formação de professores no Brasil é regida oficialmente pelas Diretrizes Curriculares Nacionais definidas na Resolução CNE/CP n 2 2, de 20 de dezembro de 2019 (BRASIL, 2020). É com base neste documento que os currículos e projetos pedagógicos são construídos. No que se refere às especificidades da formação para a docência em Matemática, segue-se o estabelecido pelo Parecer CNE/CES 1.302/2001 (BRASIL 2002), que aprova as Diretrizes Curriculares Nacionais para os Cursos de Matemática, Bacharelado e Licenciatura.

Na Resolução de 2019, a palavra "tecnologia" aparece apenas no anexo, em cinco trechos. O primeiro apresenta uma das competências gerais do docente, transcrito a seguir.

Compreender, utilizar e criar tecnologias digitais de informação e comunicação de forma crítica, significativa, reflexiva e ética nas diversas práticas docentes, como recurso pedagógico e como ferramenta de formação, para comunicar, acessar e disseminar informações, produzir conhecimentos, resolver problemas e potencializar as aprendizagens (BRASIL, 2020, p. 13).

$\mathrm{Na}$ dimensão da prática profissional, há uma orientação quanto às habilidades necessárias ao planejamento de ações de ensino, conforme trecho abaixo.

Realizar a curadoria educacional, utilizar as tecnologias digitais, os conteúdos virtuais e outros recursos tecnológicos e incorporá-los à prática pedagógica, para potencializar e transformar as experiências de aprendizagem dos estudantes e estimular uma atitude investigativa (BRASIL, 2020, p. 17).

"Usar as tecnologias apropriadas nas práticas de ensino" (BRASIL, 2020, p. 18) é uma habilidade a ser empregada na competência específica de condução das práticas pedagógicas dos objetos do conhecimento. Já na dimensão do engajamento profissional, para o comprometimento com o próprio desenvolvimento profissional, deve-se "promover o uso ético, seguro e responsável das tecnologias digitais" (BRASIL, 2020, p. 19) e para o engajamento 
profissional com as famílias e a comunidade, as tecnologias de informação e comunicação devem ser consideradas como recursos de interlocução.

Desta forma, vê-se que a função das Tecnologias Digitais (TD) vai além do domínio na utilização de softwares ou equipamentos eletrônicos para usos pedagógicos. As TD na formação inicial também requerem dos atores educacionais uma melhor compreensão do contexto dado pela presença da internet, das mídias, das redes sociais e de tudo que constitui a cultura no ciberespaço: a cibercultura ${ }^{1}$.

Já nas Diretrizes específicas para a formação de professores de Matemática o termo "tecnologia" aparece apenas duas vezes. A "capacidade de compreender, criticar e utilizar novas idéias e tecnologias para a resolução de problemas" (BRASIL, 2002, p. 3) está entre as competências e habilidades a serem desenvolvidas mediante o currículo da licenciatura e o uso de tecnologias que "possam contribuir para o ensino de matemática" (BRASIL, 2002, p. 6) além do computador - deve ser incentivado ao longo de todo o curso.

Percebe-se, então, certa escassez de orientações quanto ao uso de TD na formação inicial do professor de Matemática. Levando em consideração que vivemos em um mundo permeado por smartphones, aplicativos, internet, comércio online etc, e estando a Educação inserida neste contexto, seria razoável uma maior presença das TD na formação de professores. Isso não apenas através da inclusão de recursos didáticos digitais, mas principalmente para melhor lidar, em termos pedagógicos e interpessoais, com os estudantes da escola, que já nascem mergulhados na cibercultura.

Porém, algumas pesquisas apontam deficiência na formação com TD. Gatti e Nunes (2009) fizeram uma análise de 31 cursos de licenciatura em Matemática do Brasil sob diversos aspectos, mostrando que os conteúdos específicos da área ocupam pouco mais de 30\% da carga horária total dos cursos, em média. Incluído aí está 1,7\% de carga horária destinada aos saberes relacionados às tecnologias.

Mesquita (2020) verificou que nos Projetos Pedagógicos de Curso (PPC) dos treze cursos regulares e presenciais de licenciatura em Matemática de instituições públicas do estado do Ceará, apenas nove apresentam as TD no currículo. Esse uso se resume a alguns softwares tais como Cabri Géomètre, Régua e Compasso, GraphMatica, MatLab e Derive, na maior parte

\footnotetext{
${ }^{1}$ Para Lévy (2010), a cibercultura é o "conjunto de técnicas (materiais e intelectuais), de práticas, de atitudes, de modos de pensamento e de valores que se desenvolvem juntamente com o crescimento do ciberespaço" (LÉVY, 2010, p. 17). Santaella (2003) caracteriza o ciberespaço como um conjunto de tecnologias que permitem os seres humanos interagir em ambientes simulados.
} 
em disciplinas isoladas e sem indicação da utilização destes programas de maneira transversal nos demais componentes curriculares. Como alerta a autora, é possível que se faça uso de TD por iniciativa particular dos professores, mas nos PPC não foram observadas.

Há, portanto, indícios de que a formação inicial de professores de Matemática carece de uma presença efetiva das TD. O uso de elementos característicos da Era Digital, que potencialmente são mais próximos dos estudantes contemporâneos, ainda não está consolidado. Menos ainda a discussão acerca dos usos das TD em termos mais gerais, tais como, mídias sociais, redes sociais, aprendizagem móvel, pensamento computacional etc.

Neste trabalho, trazemos relatos de vivências no âmbito da formação em cursos de licenciatura em Matemática de uma universidade pública no interior do Ceará. Apresentamos situações experienciadas em três contextos e disciplinas diferentes: uma turma de Análise Real no último semestre de um programa federal de formação de professores, uma turma de Cálculo I deste mesmo programa (mas em outra cidade) e uma turma de Matemática Básica III Polinômios e Números Complexos do curso regular na cidade sede da universidade.

Nas três situações, em comum houve o uso do software GeoGebra, projeto iniciado em 2001 pelo matemático austríaco Markus Hohenwarter. Trata-se de um software no qual podem ser trabalhados principalmente geometria e álgebra, mas que abrange praticamente todos os conteúdos curriculares da matemática escolar. Portanto, de grande potencial para o ensino de Matemática.

Com estes relatos, exemplificamos como o conhecimento matemático pode ser construído ao se incluir uma TD, em especial o GeoGebra. Considerando-se os contextos de formação de professores de Matemática, vemos que o coletivo formado por humanos e tecnologias - professores em formação e GeoGebra - atua sob mais de uma perspectiva. A discussão acerca do que foi observado nestas situações são postas nas duas últimas seções deste artigo.

\section{FormaÇÃo de PROFESSORES de MATEMÁtiCA ALÉM dA LOUSA}

Os relatos aqui apresentados baseiam-se nas vivências experienciadas por um dos autores. São decorrentes de disciplinas realizadas em três turmas distintas de formação de professores de Matemática em cidades no interior do estado do Ceará. Por meio de constantes questionamentos se deu a busca pelo significado das ações dos atores envolvidos, revelando suas perspectivas frente às situações vividas no uso do GeoGebra e que incidem sobre a formação docente. 
Esse olhar caracteriza, segundo Bogdan e Biklen (1994), uma investigação qualitativa. Dentre as várias formas que esta pode assumir tem-se a pesquisa-ação, que busca a transformação de uma realidade na qual os participantes estão inseridos e com o pesquisador também assumindo o papel de participante, ou seja, "uma pesquisa de transformação, participativa, caminhando para processos formativos" (FRANCO, 2005, p. 487).

A pesquisa-ação não é propriamente uma prática, mas também não é uma pesquisa científica tradicional, uma vez que altera o que está sendo investigado. Porém, há intersecções com essas duas áreas (TRIPP, 2005). Ao assumir o ensino como objeto de estudo dentro de uma metodologia de pesquisa-ação, Penteado (2010) define a pesquisa-ensino como aquela "realizada durante e como ato docente, pelo profissional responsável por essa docência" (PENTEADO, 2010, p. 36).

Para a autora, o que motiva a pesquisa-ensino é o desejo de transformação da prática docente a partir de alguma insatisfação do professor. Ao realizar uma pesquisa-ensino o professor de sala de aula passa a ser denominado professor-pesquisador e busca entender as “interações humanas que se corporificam no desenvolvimento do processo de ensinoaprendizagem, durante o exercício da docência” (PENTEADO, 2010, p. 37).

Além das interações humanas, podemos observar também as interações das pessoas com as tecnologias. Borba e Villarreal (2005) discutem a ideia de conhecimento que se constrói na coletividade humanos-tecnologias partindo do conceito de reorganização do pensamento construída pelo psicólogo russo Oleg Konstantinovich Tikhomirov. O computador/smartphone e o GeoGebra, não substituem ou suplementam o pensamento humano. Também não são meros utensílios a serviço dos humanos, mas reorganizam a maneira como pensamos. Têm um papel semelhante ao da linguagem na Teoria de Vygotsky.

Humanos, ao mesmo tempo, transformam e são transformados pelas tecnologias. Por exemplo, a invenção da imprensa reconfigurou a maneira de distribuição da informação. A internet mudou a relação entre as pessoas e a informação, permitindo que esta também possa ser produzida por aqueles que antes eram apenas os receptores do conteúdo distribuído de maneira massiva, a partir de poucos centros. Ora, mas todo esse desenvolvimento tecnológico foi realizado por humanos. Portanto, não há motivos para uma visão dicotômica entre humanos e tecnologias.

As tecnologias consolidadas no meio escolar e universitário são a oralidade e a escrita. Ou seja, o falar do professor e o registro do aluno. Mais especificamente a extensão de nossa 
memória por meio do registro escrito ou da tradição oral, sendo que ambas têm em comum a linearidade. Uma história - ou uma aula - que se baseia apenas nessas duas tecnologias é dita ou escrita segundo uma sequência que, se não for mantida, pode perder o sentido ou ser descaracterizada.

Lévy (2010) classifica oralidade, escrita e tecnologias informáticas como as principais ferramentas associadas com memória e conhecimento, sendo que a terceira se diferencia qualitativamente das duas primeiras pelo fato de que o raciocínio - na presença desta tecnologia - é desafiado por outras maneiras de pensar (BORBA; VILLAREAL, 2005). A linearidade agora dá lugar à hipertextualidade. Os computadores, as mídias, as redes e todo o aparato próprio da cibercultura, tornam a comunicação independente de uma sequência preestabelecida. Textos da internet que possuem links para outros textos, vídeos e imagens; vídeos no YouTube que fazem referências a outras mídias; o saltitar entre janelas no computador ou entre aplicativos nos smartphones. Essas e outras ações só puderam existir com a consolidação do ciberespaço e as tecnologias que foram desenvolvidas desde então.

Assim, o estudante contemporâneo, de todos os níveis de ensino, não está limitado ao consumo. Ele também pode produzir conhecimento. Um conhecimento qualitativamente diferente, produzido por um novo coletivo pensante (BORBA; VILLARREAL, 2005), dada a inclusão de outras tecnologias ao pacote composto pela oralidade e pela escrita.

Pensar num ensino de Matemática que incorpore as TD deve ser encarado como possibilidade para a produção de conhecimento qualitativamente diferente. Mas qual a necessidade de pensar em uma maneira diferente para o ensino? Entendemos que se faz necessária esta discussão tendo em vista que os jovens que ingressam nos cursos de licenciatura atualmente serão os professores que lidarão com os ainda mais jovens estudantes das escolas de Educação Básica. Essas duas classes de indivíduos, em grande parte, nasceram em um contexto no qual as TD estão extremamente presentes em seus cotidianos. Por tudo isso, é preciso refletir sobre a formação dos professores para a realidade e as demandas da contemporaneidade.

Deste modo, as vivências relatadas a seguir constituem-se não somente como oportunidade de incremento do repertório dos professores em formação por meio do uso de mais um software, mas também como janelas que permitem ao futuro docente ampliar seus horizontes no que se refere à interligação entre os conteúdos matemáticos curriculares. Mais ainda: estes relatos revelam, em certa medida, a necessidade de mudança de ponto de vista dos 
professores formadores - os acadêmicos -, convidando-os a refletir e promover uma formação para o ensino de Matemática que vá além da lousa.

\section{O GeoGebra eM UMA TURMA de CÁlCulo I}

A universidade na qual um dos autores trabalha possui parceria com um programa federal de formação de professores para a Educação Básica. Através deste programa outras cidades - via Secretarias Municipais de Educação - podem se candidatar a receber cursos de licenciatura em caráter intensivo, desde que haja demanda no município. Os cursos ofertados têm os mesmos currículos das licenciaturas que acontecem de maneira regular na sede da universidade. As diferenças se dão pela ocorrência das aulas (sextas e sábados nos turnos manhã e tarde, e de segunda a sábado em período de férias escolares), pelo local dos encontros (geralmente uma escola da rede municipal), pelo corpo docente (que pode contar com professores que não fazem parte do colegiado do curso na universidade) e pela forma de ingresso (que se dá por seleção independente).

Uma das disciplinas mais temidas pelos estudantes da área de Ciências Exatas é o Cálculo I. O medo se dá, em grande parte, pelos altos índices de reprovação. Porém, deve-se considerar que os conceitos abordados nesta disciplina são um tanto quanto diferentes daquilo que se entende - até então - por Matemática. Saem as contas puramente aritméticas e aplicações de fórmulas, entram épsilons e deltas. Aparecem as ideias de limite e derivada. Para amenizar os efeitos desta abstração que traz várias dificuldades aos estudantes, a utilização de gráficos é importantíssima no ensino de Cálculo (HELLMANN et. al, 2016; RICARDO; SANTOS, 2018; MARTINS JÚNIOR, 2015).

Ocorre que, na presença apenas de tecnologias como caderno, lápis, quadro e pincel (ou giz), a construção de gráficos pode se tornar deveras problemática. Em primeiro lugar, o professor deve ter habilidade na construção de figuras no quadro para que este seja realmente um recurso facilitador da aprendizagem, e não o contrário. Em seguida, se também o estudante não tiver habilidades suficientes para reproduzir ou esboçar novas situações em seu caderno, a frustração pode se estabelecer.

Mesmo que exista em sala de aula uma situação altamente favorável no que se refere às habilidades para construção de gráficos, há um fato do qual não se pode fugir: as imagens construídas no quadro e nos cadernos são fixas. Para cada mudança de situação, por menor que seja, será necessário um novo desenho ou a inserção de mais informações sobre uma figura já produzida: uma reta secante com outra inclinação, mais pontos sobre o gráfico ou, até mesmo, 
outro gráfico com todas estas informações. A inclusão de novos elementos sobrepondo-se ao gráfico pode dificultar a leitura da imagem produzida.

Considerando-se todas essas possibilidades e a relativa facilidade no acesso ao GeoGebra, na disciplina de Cálculo I de uma das turmas de licenciatura em Matemática do projeto federal de formação de professores, optou-se por fazer uso do software junto com os estudantes. Este curso se desenvolve em uma cidade da região noroeste do estado do Ceará, distante $303 \mathrm{~km}$ da capital Fortaleza. Vinte estudantes frequentaram a disciplina que aconteceu entre agosto e setembro de 2019.

Uma vez que o local dos encontros não dispunha de laboratório de informática no qual se pudesse usar o GeoGebra, fora solicitado pelo professor que os estudantes instalassem o aplicativo em seus respectivos smartphones. Esse processo pode ser feito diretamente dos aparelhos com acesso à internet ou, ainda, usando a versão online disponível no site do projeto 2 . A partir do segundo encontro iniciou-se a utilização da ferramenta, com o professor usando uma versão em seu computador pessoal e projetando as imagens na parede da sala. Como as versões para computador e smartphone têm layout distintos, o professor também fez uso da versão para smartphone a fim de oferecer um melhor suporte aos estudantes.

A disciplina ocorreu no terceiro semestre do curso e a maior parte dos estudantes não conhecia o software. Não utilizaram o GeoGebra enquanto estudantes da Educação Básica e também afirmaram que não fizeram uso do software nos dois primeiros semestres do curso. Pelos relatos, outros professores do curso de licenciatura já haviam usado o GeoGebra em suas aulas expositivas, mas apenas como maneira de ilustrar suas intervenções, ou seja, um indício de uso domesticado das TD (BORBA; PENTEADO, 2002). Alguns estudantes que já atuavam como professores na Educação Básica disseram usar algumas vezes nas suas aulas, mas sem envolver seus aprendizes no processo.

A proposta foi, então, o uso do GeoGebra diretamente pelos próprios estudantes para auxiliar na resolução de problemas que geralmente são trabalhados apenas com aplicação de técnicas (algébricas) de resolução de limites e derivadas. A título de ilustração, consideremos a determinação do limite abaixo.

$$
\lim _{x \rightarrow 1}\left(\frac{1}{x-1}\right)
$$

\footnotetext{
${ }^{2}$ www.geogebra.org. 
Com o suporte do GeoGebra, a compreensão dos limites laterais se torna mais acessível aos alunos bem como a não existência do limite. Além disso, modificar a função e perceber de imediato as mudanças no gráfico (descontinuidades, assíntotas e limites no infinito, como mostra a Figura 1) são possibilidades que, sem o GeoGebra, seriam de difícil implementação. Assim, na presença desta TD e a maneira como se aborda, por exemplo, o conceito de limite, a aprendizagem ocorre de maneira diferente.

Figura 1 - Gráfico da função $f(x)=\frac{1}{x-1}$ e assíntota vertical $x=1$

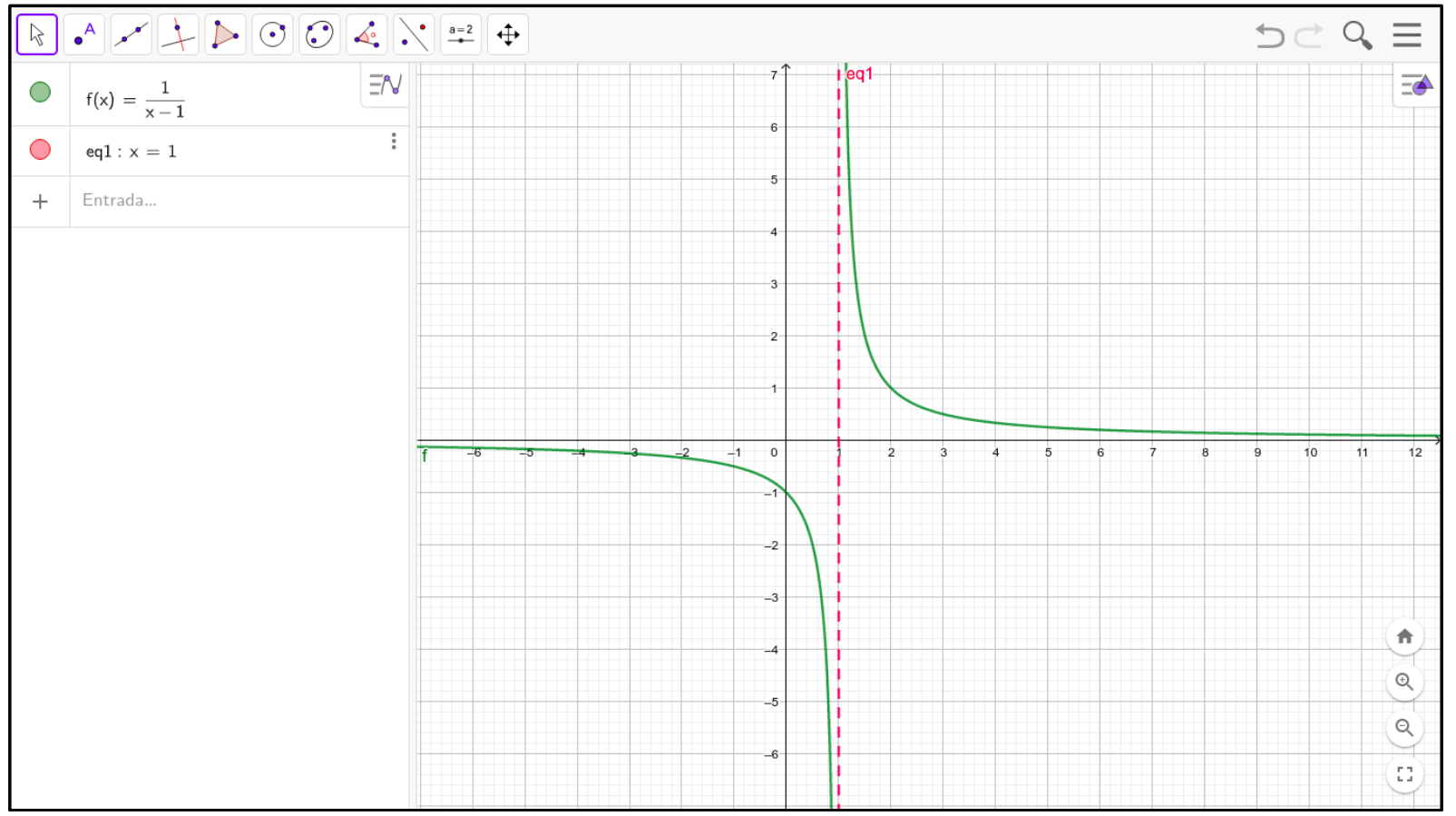

Fonte: Print Screen do GeoGebra em sua versão online.

A experiência de ensino de Cálculo I nessa turma não acabou de vez com a concepção de dificuldade desta disciplina, mas, certamente, os professores em formação puderam perceber situações em que seria mais difícil - talvez impraticável - o uso apenas de tecnologias não digitais como papel e lápis, por exemplo.

No que diz respeito ao professor formador, certamente a dinâmica da aula é alterada. A adoção do GeoGebra como recurso pedagógico que é usado conjuntamente pelos estudantes, complementa a aula tradicional de Cálculo I. O olhar dos alunos é deslocado da lousa em direção às telas dos smartphones sem, contudo, alijar o professor do processo. Agora o docente interage de maneira personalizada com cada estudante ao mesmo tempo em que os discentes também podem interagir entre si. Esmaece a entrega/recepção do conteúdo e brilha a construção coletiva: estudantes-smartphones-GeoGebra-professor. 


\section{O GEOGEbRa EM UMA TURMA de ANÁLISE REAL}

O segundo relato que trazemos é da disciplina Análise Real, no último semestre de outro curso de licenciatura em Matemática no mesmo programa federal de formação de professores citado anteriormente. A disciplina foi ministrada em fevereiro de 2020 em outra cidade do noroeste do Ceará, distante $332 \mathrm{~km}$ de Fortaleza.

Enquanto o Cálculo I é temido por boa parte dos estudantes de cursos na área de Ciências Exatas, a disciplina de Análise Real pode causar sensações ainda piores nos estudantes de um curso de Matemática. O temor quanto ao Cálculo I se acentua pelo fato de esta ser uma disciplina com alto índice de reprovação. Já em Análise Real, o nível de abstração deste conteúdo curricular exige do estudante uma maneira diferente de ver a Matemática. Não há aplicação de fórmulas ou obtenção de técnicas tais como para derivadas ou integrais.

No planejamento da disciplina optou-se pelo uso do GeoGebra como ferramenta pedagógica. Como o estudo de sequências numéricas e séries infinitas faz parte do conteúdo programático da disciplina, resolveu-se fazer uso do GeoGebra para assim como no caso da turma de Cálculo I descrito na seção anterior, melhorar a visualização de conceitos que são mais abstratos.

Apesar de ser o último semestre desta turma, os estudantes foram categóricos em afirmar que jamais tiveram contato com o GeoGebra dentro do curso. Algo, ao nosso ver, preocupante, dada a potencialidade deste software para o ensino de Matemática e por se tratar de um curso de formação de professores. Contudo, todos os alunos possuíam smartphone (alguns também levaram notebook) e instalaram sem grandes dificuldades o aplicativo GeoGebra em seus respectivos aparelhos. Ao todo, vinte estudantes cursaram a disciplina.

A partir do segundo encontro começou-se a usar o aplicativo para inferir a convergência ou não de sequências numéricas. Por exemplo, o comando abaixo informa ao GeoGebra a expressão de uma sequência (por exemplo, $a_{n}=1 / n$ ), a variável (neste caso, $n$ ), o valor inicial (de n) e o valor final (também de n) dos termos.

$$
\text { Sequência }(<\text { Expressão }>,<\text { Variável }>,<\text { Valor Inicial }>,<\text { Valor Final }>)
$$

Obviamente não é possível construir uma sequência infinita com o GeoGebra pois, se o fosse, por maior velocidade de processamento que o computador pudesse ter, ele estaria fazendo cálculos por todo o sempre. Então, já na implementação da sequência no aplicativo pode-se discutir quantos termos utilizar para que se tenha noção da convergência (ou divergência) da sequência. 
Com o comando "Sequência", o GeoGebra retorna uma lista de números, ou seja, a própria sequência. A partir da leitura desta lista, os estudantes discutiram a convergência/divergência da sequência, aumentando o parâmetro "valor final" - e consequentemente a quantidade de termos - quando necessário. Observaram também que não aparecia um gráfico. A janela de visualização permanecia inalterada exercício após exercício, como mostra a Figura 2.

Figura 2 - A janela de visualização observada com os dez primeiros termos gerados da sequência

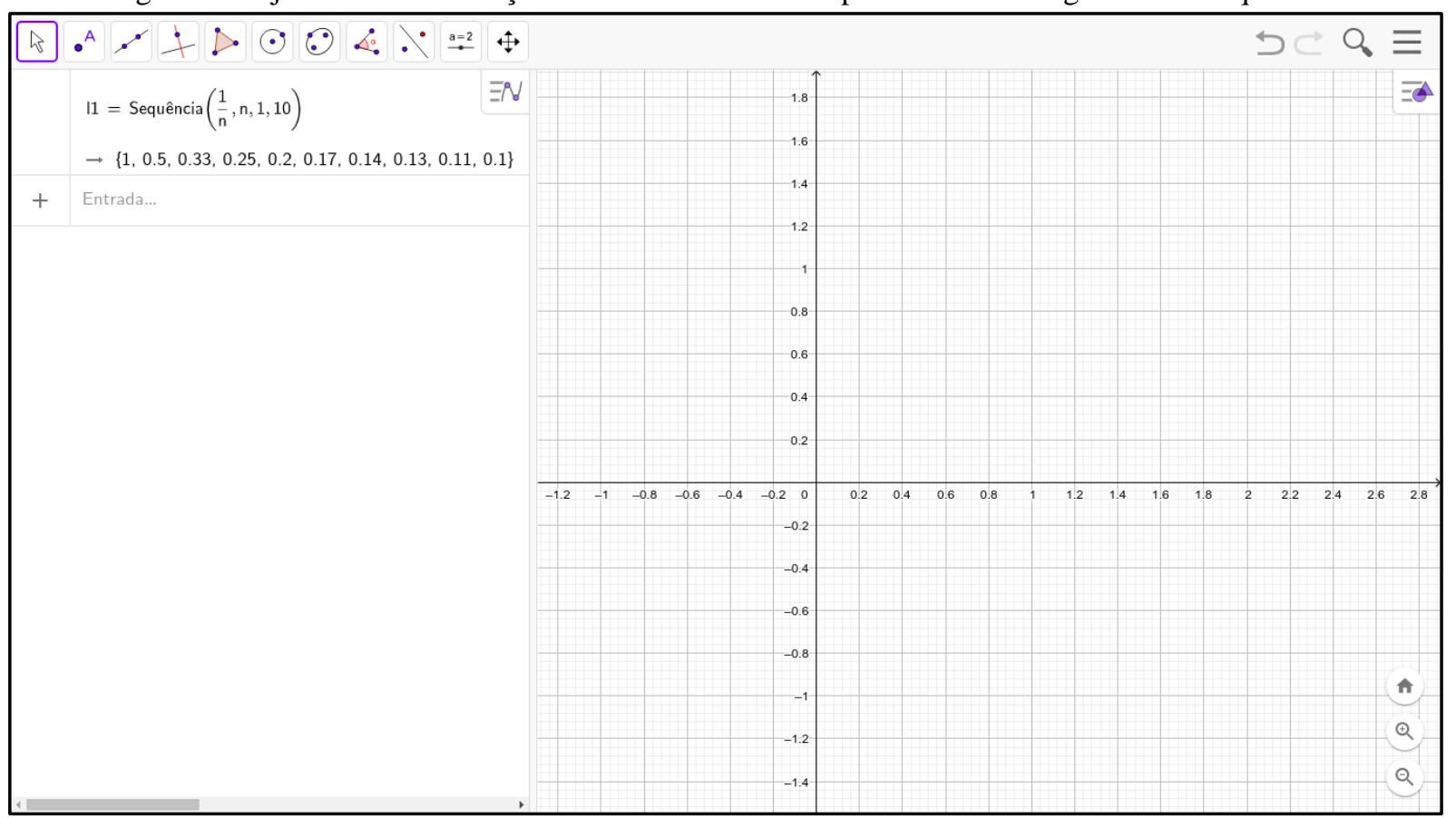

Fonte: Print Screen do software GeoGebra.

Após alguns questionamentos e reflexões, a turma entendeu que para gerar um gráfico seria necessário formar pares ordenados de maneira explícita. Embora cada termo da sequência esteja associado a um número natural (a posição dentro da sequência), isto é, cada termo é a imagem de um elemento (conceito de função), esta informação não estava explícita no comando. Após sugestões, a turma chegou ao comando abaixo para implementar, finalmente, o gráfico da função $f(n)=\frac{1}{n}$, com n natural variando no conjunto $\{1,2,3,4,5,6,7,8,9,10\}$.

$$
\text { Sequência }\left(\left(n, \frac{1}{n}\right), n, 1,10\right)
$$

Assim, seria possível visualizar o gráfico da função que gera a sequência (imagens da função) obtendo uma melhor compreensão acerca do seu comportamento, como mostra a Figura 3. 
Figura 3 - A sequência $\frac{1}{n}$ representada como o gráfico da função $f(n)=\frac{1}{n}$ com n natural

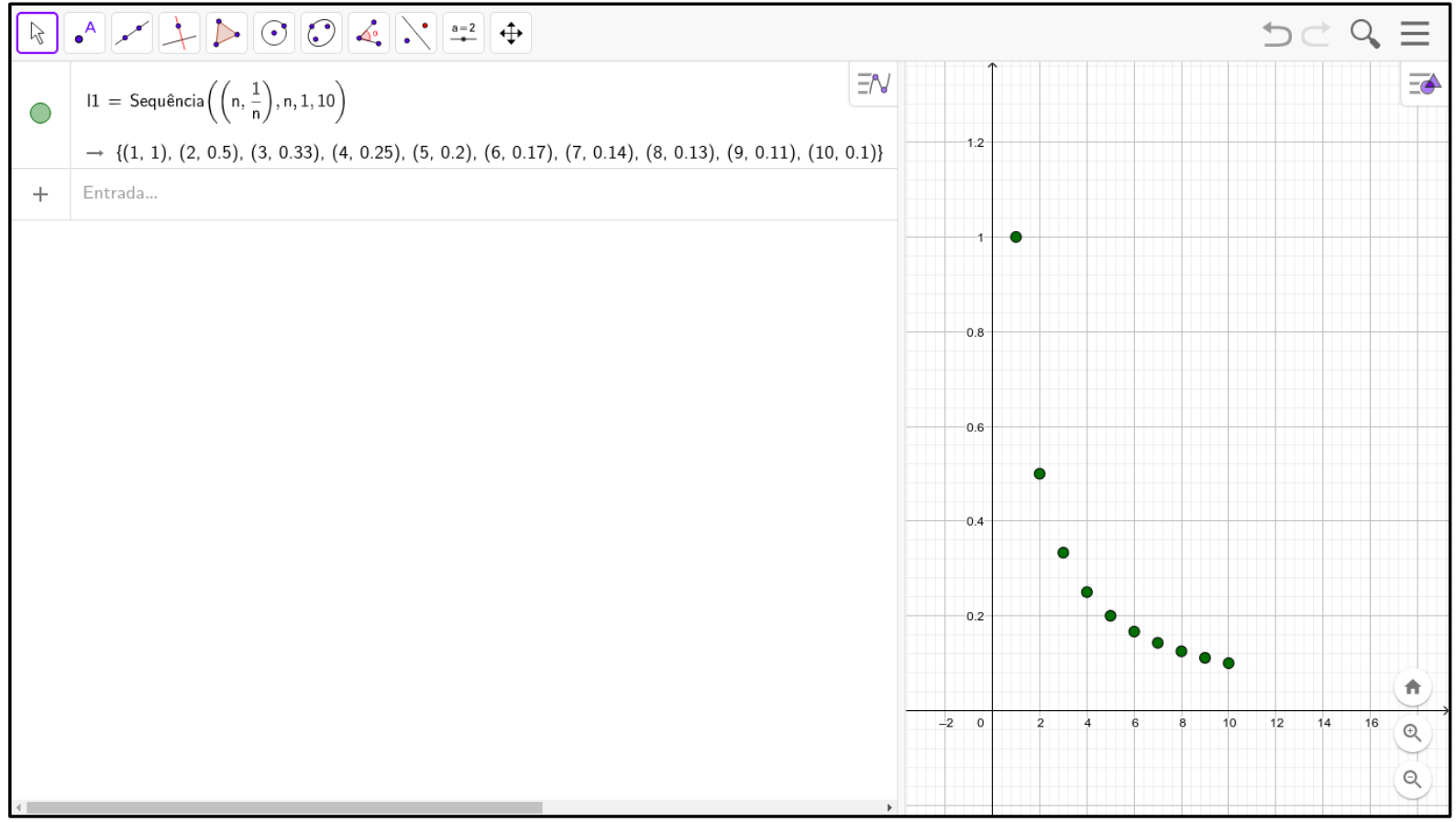

Fonte: Print Screen do software GeoGebra.

Novamente, observam-se os sinais de que na presença de TD - smartphones e GeoGebra - os estudantes produzem o conhecimento de maneira qualitativamente diferente. $\mathrm{O}$ que na escola é visto sob o título de progressão aritmética ou geométrica agora é entendido como caso particular de uma sequência numérica que, por sua vez, é uma função cujo domínio é o conjunto dos números naturais. Verifica-se também que, na verdade, gráficos são subconjuntos de $\mathrm{R}^{2} \mathrm{e}$ o "desenho" é a sua representação geométrica. Mais ainda: constata-se que nem todo gráfico é linha contínua; existem gráficos discretos, isto é, que podem ser representados por pontos isolados no plano cartesiano como mostra a Figura 3.

Todos esses "novos" conhecimentos e as ligações entre assuntos que antes eram vistos isoladamente vão sendo construídos à medida que o estudante faz pequenos ajustes nos dados que fornece ao software como, por exemplo, a expressão da função ou a quantidade de termos. Daí, novas situações são criadas e interpretadas de maneiras qualitativamente diferentes das que seriam geradas apenas com o uso das mídias papel, lápis, lousa, pincel (ou giz).

Assim, o uso do GeoGebra como recurso pedagógico pode ser um complemento na compreensão dos conceitos tratados na disciplina de Análise Real. O alto nível de abstração e as lousas repletas de demonstrações nas quais pouco aparecem algarismos arábicos, seguem sendo importantes e necessários, porém não é preciso acreditar que outros recursos não possam contribuir para a aprendizagem dos estudantes (professores em formação). Não percamos de 
vista os objetivos de um curso de licenciatura em Matemática, essencialmente diferentes dos de um bacharelado.

\section{Geogebra em uma turma de Matemática Básica III - Polinômios e Números COMPLEXOS}

O terceiro relato que trazemos trata de uma disciplina ministrada no curso regular de licenciatura em Matemática na sede da universidade. A instituição estadual e pública está localizada também na região noroeste do Ceará, a $231 \mathrm{~km}$ de Fortaleza. Devido a pandemia de COVID-19, a disciplina "Matemática Básica III - Polinômios e números complexos”, ofertada para os estudantes do segundo período do curso, foi realizada de modo remoto. As atividades tiveram início em 3 de novembro de 2020 e se encerraram em 25 de fevereiro de 2021.

Foram 49 os estudantes matriculados na disciplina mencionada. Porém, foi registrada uma frequência semanal em torno de 30 estudantes. Os encontros aconteceram de maneira síncrona e sistemática nas noites de quarta-feira através de uma plataforma de videoconferência. Embora no nome da disciplina os polinômios apareçam antes, iniciou-se pelo estudo dos números complexos.

Em oportunidades anteriores na condução desta disciplina, foi escolhido o caminho da definição dos números complexos a partir de operações com pares ordenados. Definindo a adição e a multiplicação de pares ordenados e demonstrando algumas propriedades, a estrutura algébrica de $\mathrm{R}^{2}$ fica bem organizada e, a partir daí, basta fazer uma mudança de notação para se chegar a forma algébrica $a+b i$ de um número complexo, onde $a$ e $b$ são números reais e $i$ é chamada unidade imaginária, isto é, um número não real tal que $i^{2}=-1$.

Por este caminho há uma questão que, particularmente, nos incomoda. Com pares ordenados, a definição de multiplicação ${ }^{3}$ aparece como "mágica" e carece de uma melhor justificativa. Funciona e nos permite demonstrar as propriedades desta operação, além de avançar para a notação algébrica, mas não parece clara para o estudante a razão da multiplicação não ser tão direta quanto a adição ${ }^{4}$ de pares ordenados. Assim, depois de conhecermos a abordagem do professor Carlos Mathias para definição do conjunto dos números complexos, escolheu-se o caminho guiado pelo conceito de ampligiros (MATHIAS, 2013), descrita a seguir.

\footnotetext{
${ }^{3}(a, b) \cdot(c, d)=(a c-b d, a d+b c)$

${ }^{4}(a, b)+(c, d)=(a+c, b+d)$
} 
Inicialmente realiza-se uma interpretação geométrica para a soma e o produto de números reais, vistos como pontos na reta real. Em seguida, depois de considerar o problema que surgiu com as resoluções de equações do terceiro grau ${ }^{5}$, nas quais podem aparecer raízes quadradas de números negativos, percebe-se que não há como "driblar" a questão apenas na reta real. É preciso pensar fora da reta. Assim, chega-se à definição de um número complexo como a composição de uma homotetia (ampliação ou redução de tamanho a partir de um ponto fixo) e uma rotação (giro em torno da origem do plano) do segmento OA, onde $\mathrm{O}$ é a origem da reta real e A é o ponto de coordenadas $(1,0)$, como mostra a Figura 4.

Figura 4 - Um ampligiro de OA, isto é, uma homotetia seguida de uma rotação

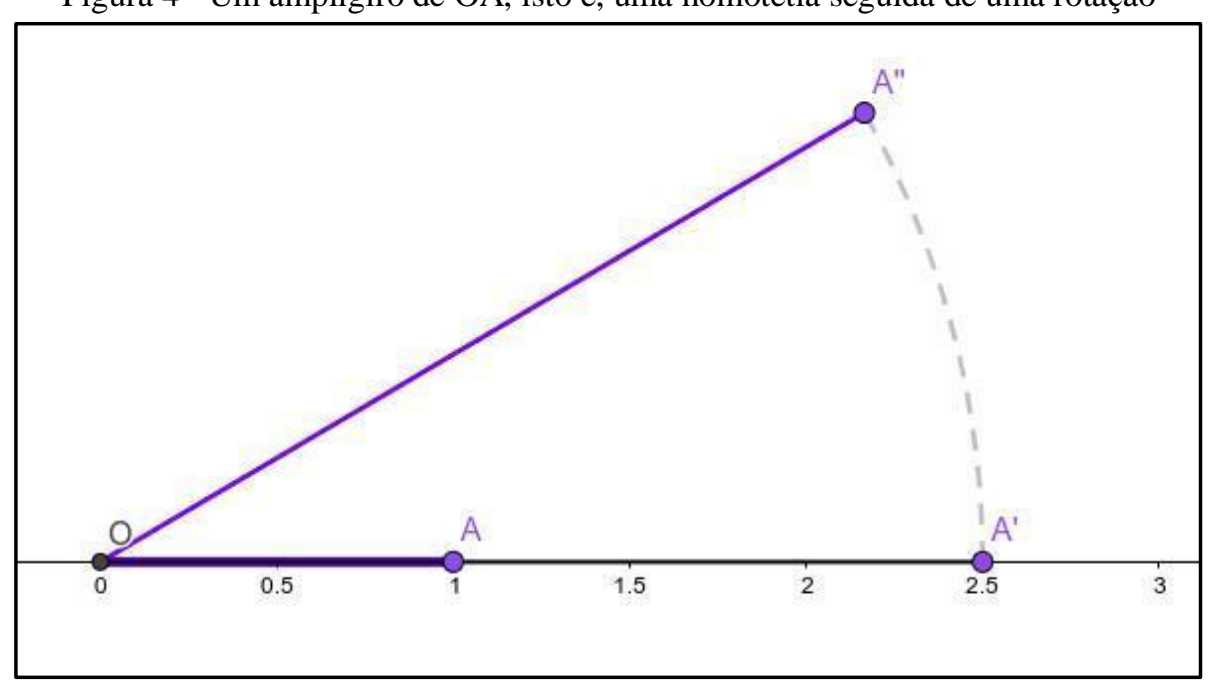

Fonte: Print Screen do software GeoGebra.

A partir da ideia de ampligiro estende-se a noção de adição e multiplicação de números reais para estes novos objetos (no plano). Somar dois números complexos significa formar uma poligonal (partindo da origem do plano) com os segmentos que os representam - respeitandose suas posições relativas aos eixos coordenados - e observar o novo ponto final (sua posição em relação à origem).

Já multiplicar dois números complexos, $\mathrm{z}_{1}$. $\mathrm{z}_{2}$, é o mesmo que ampliar (ou reduzir) o comprimento de $\mathrm{z}_{1}$ pelo comprimento de $\mathrm{z}_{2}$ e girar este novo segmento em torno da origem de um ângulo que corresponde ao ângulo entre $\mathrm{z}_{2}$ e o semi-eixo positivo das abscissas (argumento de $z_{2}$ ). Ou seja, realiza-se um ampligiro em $z_{1}$.

\footnotetext{
${ }^{5}$ A Fórmula de Cardano, em alguns casos, pode apresentar raízes quadradas de números negativos. Porém, retornando à equação, as raízes são substituídas sem problemas, desde que sejam utilizadas as propriedades da potenciação dos números reais a estas raízes de números negativos.
} 
Esta construção torna-se mais interessante quando realizada no GeoGebra, pois podemos manipular com certa facilidade essa representação dos números complexos. Com encontros ocorrendo somente em salas de aula virtuais, além de acompanhar as construções feitas pelo professor, os estudantes também podem praticar individualmente em seus smartphones ou computadores, uma vez que foram convidados a instalar o aplicativo ou utilizar a versão online. No entanto, vale registrar que, pela dinâmica das aulas remotas, o acompanhamento do professor aos estudantes fica um tanto quanto comprometido, pois não há a possibilidade de visitar cada aluno individualmente como é feito na sala de aula concreta.

Além de buscar discutir com os estudantes - nos encontros síncronos - as consequências desta outra abordagem (significados, propriedades, relação com o que eles já sabiam sobre os números complexos), também foram usados recursos como os applets ${ }^{6}$, inclusive incentivando os estudantes a criarem os seus. Também foram disponibilizados textos com roteiros para as construções no GeoGebra. Desta forma, acreditamos que tendo como ferramentas principais o smartphone e o GeoGebra e não apenas caderno e lápis, o conhecimento dos estudantes acerca dos números complexos é construído de maneira qualitativamente diferente.

Essa abordagem também permitiu relacionar o conteúdo de números complexos com o de transformações no plano, que se encontra ainda deficitário no repertório do professor da Educação Básica, porque não estudaram ou não discutiram o assunto na formação inicial (MALCHER JÚNIOR; JUCÁ, 2019). Uma vez que o estudante da licenciatura ainda cursará disciplinas que tratam especificamente das transformações do plano, vemos como benefício para o professor em formação a apreensão de algumas noções básicas deste assunto com o suporte do GeoGebra.

Percebe-se, novamente, a proposta de mudança no centro de gravidade. Com o isolamento social e o surgimento do ensino remoto, ocorre a tentação de se repetir nas plataformas de videoconferência o modelo transmissivo ainda predominante nas aulas presenciais (antes da pandemia). Com a temporada de ensino remoto, as apresentações em slides e/ou o uso de mesas digitalizadoras para apresentar aos estudantes o conteúdo da aula de Matemática parecem predominar. Porém, vemos que lançando mão de recursos como o GeoGebra, por exemplo, o professor permite que o estudante participe de maneira ativa, não se limitando a apenas receber o que o professor transmite.

\footnotetext{
${ }^{6}$ Construções no GeoGebra previamente realizadas pelo professor e disponibilizadas em https://www.geogebra.org/u/mharcius 23 .
} 
Contudo, o modelo de ensino baseado essencialmente em transmissão é tão enraizado na cultura escolar e universitária que mesmo nesta disciplina, a segunda parte - polinômios foi conduzida de forma que o uso de mesa digitalizadora para resolução de exercícios foi mais frequente que na primeira parte, a pedido dos próprios estudantes.

Investir em um ensino remoto que incentiva o estudante a não apenas assistir uma aula como quem assiste - com menor motivação, muitas vezes - um vídeo no YouTube, exige tempo do professor. Tempo para planejar o uso destes recursos e para prever o desenrolar das situações sobre as quais o professor tem menos controle ainda, se comparado ao ensino presencial. Antes o estudante tinha à sua vista, quando muito, as poucas janelas da sala de aula física. Agora as janelas estão à disposição em maior variedade nas telas de seu smartphone ou computador, cujo acesso é facilitado pela impossibilidade de contato visual com o professor por um simples desligar de câmera por parte do estudante.

O GeoGebra se mostrou de grande valia não apenas pela possibilidade de uso nos encontros síncronos, como também pelo uso como uma potente "calculadora" à mão do estudante em todos os momentos através do smartphone. Assim como no caso da disciplina de Cálculo I, os esquemas utilizados para entender a ideia de ampligiros poderiam ser inviáveis apenas com o uso de lousa (em encontros presenciais) ou mesa digitalizadora (no caso dos encontros síncronos). O dinamismo proporcionado pelo GeoGebra e a possibilidade de explorar os applets ajudam o estudante no processo de aprendizagem deste conteúdo curricular.

Além disso, esta disciplina se diferencia das duas outras citadas nas seções anteriores pelo fato de que seu conteúdo está explicitamente presente na Educação Básica. Desta forma, os professores em formação além de utilizar o GeoGebra como ferramenta de aprendizagem, também utilizaram o software numa perspectiva de futuro, vislumbrando seu uso como recurso pedagógico para o ensino de Matemática.

Ademais, acreditamos que há incertezas quanto à forma de condução do ensino num cenário pós-pandemia. Em que medida as práticas adotadas no ensino remoto serão continuadas no ensino presencial? Desta forma, os professores em formação não apenas ampliaram suas habilidades quanto ao uso do GeoGebra como também poderão utilizar este software com maior segurança para o ensino de Matemática em cenários híbridos.

\section{Professorandos-COM-GEOGEBRA: POSSIBILIDADES PARA A FORMAÇÃO}

Pelos relatos acima, vê-se grandes possibilidades para o ensino de Matemática com o suporte do GeoGebra. Mesmo em diferentes contextos é possível promover o ensino de 
Matemática de forma que o estudante possa realizar conexões entre diversos assuntos, inclusive os já estudados anteriormente.

Para o professor é importante criar oportunidades em que o mesmo assunto possa ser examinado mais de uma vez e em diferentes contextos [...]. A consolidação, resultante de novas conexões entre as células nervosas e do reforço de suas ligações, demanda tempo e nutrientes e, portanto, não ocorre de imediato. Não aprendemos tudo o que estudamos de um dia para o outro e muito menos o que apenas presenciamos em sala de aula (COSENZA; GUERRA, 2011, p. 73).

Nas três turmas, além das diferenças entre as cidades, entre as rotinas dos cursos, das infraestruturas e das trajetórias anteriores dos estudantes, observamos que os discentes se encontravam em momentos distintos em suas formações. Ainda assim, foi possível observar que a inserção de TD, a saber, o smartphone e o GeoGebra, é capaz de modificar o olhar do estudante sobre o assunto. Consequentemente, o olhar do professor sobre a aprendizagem dos seus estudantes e suas próprias convicções enquanto formador, também podem ser transformados. Os relatos deste texto são do Ensino Superior, de situações experienciadas entre um professor formador e estudantes que se preparam para a docência, porém, essa mudança do olhar também pode ocorrer em nível escolar.

Por exemplo, na turma de Cálculo I havia estudantes recém-saídos do Ensino Médio e também estudantes que já atuavam como professores há mais de 25 anos. Os primeiros, naturalmente, apresentaram maior desenvoltura no uso do aparelho e do aplicativo. Porém, ao contrário do que se poderia imaginar a princípio, os mais experientes não foram resistentes ao uso do GeoGebra para as atividades propostas na disciplina. Os caminhos abertos com o uso deste software, permitindo conexões com assuntos já conhecidos, podem ter contribuído favoravelmente, confirmando o que dizem Cosenza e Guerra (2011) sobre a motivação intrínseca do cérebro em aprender aquilo que reconhece como significante.

Outra possibilidade trazida pela utilização de smartphones em sala de aula foi a discussão a respeito da legislação. No Ceará, o Artigo $1^{\circ}$ da Lei 14.146 de 24 de junho de 2008 - iniciativa do deputado estadual Artur Bruno e sancionada pelo então governador Cid Gomes - traz textualmente: "Ficam os alunos proibidos de utilizar telefone celular, walkman, discman, MP3 player, MP4 player, iPod, bip, pager e outros aparelhos similares, nos estabelecimentos de ensino do Estado do Ceará, durante o horário das aulas" (CEARÁ, 2008).

Esta lei continua em vigor atualmente. Ela não se restringe aos estabelecimentos públicos nem faz menção ao nível de ensino, englobando também o Ensino Superior. Assim, considerando os relatos acima e os contextos das escolas nas cidades do interior do Ceará - 
falta de laboratórios e serviços de internet precários -, parece razoável afirmar que esta Lei precisaria de uma profunda revisão. Ironicamente, a pandemia trouxe consigo a exigência do uso dos eletrônicos até então proibidos ou de uso controlado.

Como professores formadores percebemos o potencial do GeoGebra enquanto ferramenta pedagógica não apenas para melhorar as exposições na sala de aula, mas, principalmente, como TD que permite a atuação dos aprendizes no processo. Esse conjunto que envolve professores, estudantes, computadores/smartphones e softwares, desde que estes últimos não sejam usados de forma domesticada, viabiliza uma construção do conhecimento que é qualitativamente diferente. Nas palavras de Borba e Villarreal (2005):

[...] nós acreditamos que o conhecimento é produzido junto com uma dada mídia ou tecnologia da inteligência. E por esta razão, nós adotamos uma perspectiva teórica que reforça a noção de que o conhecimento é produzido por um coletivo composto por humanos-com-mídia ou humanos-com-tecnologias, e não, como outras teorias sugerem, por humanos individualmente ou coletivos compostos somente por humanos (BORBA; VILLARREAL, 2005, p. 23, tradução nossa).

Ao olhar especialmente para o processo de formação de professores de Matemática, o coletivo humanos-com-tecnologias se desenvolve, ao nosso ver, em duas vertentes: tanto na perspectiva da aprendizagem matemática do estudante de graduação, como na formação deste mesmo estudante como futuro professor de Matemática. Esta segunda perspectiva, na qual ousamos batizar o coletivo humanos-com-tecnologias por professorandos-com-GeoGebra, ocorre sob a forma de exploração do software em sala de aula. Surgem novos questionamentos e emergem conexões com outros assuntos, anteriormente estudados ou não.

O professorando atua numa zona de interseção entre dois objetivos: ele não só aprende como também vê nessa relação - sua com os equipamentos e os softwares - alternativas que possam levar seus futuros aprendizes a exercerem suas próprias autonomias para a construção do conhecimento. No coletivo professorandos-com-GeoGebra, o "humano" deste conjunto tem dois objetivos: aprender com tecnologias e aprender a ensinar com tecnologias.

Contudo, para que a formação do professor de Matemática aconteça em sintonia com as potencialidades das TD é necessário olhar por outros ângulos os cursos de licenciatura. Apenas criar disciplinas que tratam isoladamente o assunto, que mais se assemelham a treinamentos para determinadas ferramentas, não parece ser o melhor caminho. Assim como as tecnologias já perpassam a sociedade em praticamente todos os espaços, as TD podem potencializar significados ao longo de todo o currículo da licenciatura em Matemática. 
Esta mudança do olhar sobre o currículo passa, antes, pelos professores formadores que compõem os colegiados dos cursos. São diferentes vozes que se manifestam nos projetos pedagógicos das licenciaturas. Mudanças deste tipo exigem sensibilidade do corpo docente e conhecimento da realidade local, da qual o perfil do egresso deve estar o mais próximo possível.

Acreditamos que o uso efetivo do GeoGebra potencializa uma formação melhor sintonizada com o perfil do professor em formação e com a realidade escolar. Os estudantes que hoje ingressam nos cursos de licenciatura em Matemática são, em sua maioria, jovens nascidos neste milênio, assim como os jovens e adolescentes que estão/chegarão nas escolas. A relação destes atores educacionais - futuros professores e seus aprendizes - com as TD é, portanto, natural, uma vez que praticamente todos já nasceram na Quarta Fase das tecnologias digitais na Educação Matemática caracterizada por Borba, Silva e Gadanidis (2020). Cabe, então, aos cursos de formação encontrar os meios que proporcionem uma formação adequada com TD.

\section{CONSIDERAÇõES FinAIS}

As pesquisas com o GeoGebra apresentam, em um certo sentido, as contribuições para a formação de professores quando o foco é deslocado da lousa para as TD. O uso do software GeoGebra de maneira coletiva tem potencial para conduzir a sala de aula a, finalmente, romper com a predominância ou exclusividade de um ensino transmissivo. Os estudantes podem tirar conclusões com o apoio do professor e suporte das TD e não mais apenas observar as conclusões transmitidas pelo docente via lousa.

Aulas de matemática baseadas apenas no falar do professor e no escrever dos estudantes já vêm sentindo, há algum tempo, as interferências da cibercultura. Quer seja pelas possibilidades pedagógicas trazidas pelos aplicativos e smartphones ou, simplesmente, pela atração que tais aparelhos exercem sobre os jovens e adolescentes, sobretudo através das redes sociais.

Como Sibilia (2012) bem alerta, o modelo de escola pensado para a sociedade da modernidade já não é mais compatível com o estilo de vida da contemporaneidade. Já não se espera mais da escola formar - no sentido de dar forma - os operários para as fábricas, que precisavam ser normalizados dentro de um conjunto de regras. A sociedade idealizada na contemporaneidade tem outras metas.

Desta forma, o uso do GeoGebra numa perspectiva coletiva, na qual professor, estudantes, smartphones e software juntos constroem o conhecimento matemático de maneira 
qualitativamente diferente, requer do professorando não apenas o domínio técnico das TD, mas, sobretudo, a compreensão de que o modelo puramente transmissivo já não é suficiente para as demandas atuais. Para que este novo olhar chegue à sala de aula da Educação Básica é preciso que antes floresça nos bancos da academia um espírito de mudança. Ao professor formador está reservada uma grande parcela de contribuição neste processo. Há disposição para tanto?

Por fim, encerramos este texto observando que a pandemia e o consequente distanciamento social que provocou a suspensão das aulas presenciais nas escolas por todo o mundo pode atrasar um pouco mais este processo rumo a um ensino que se baseie no conhecimento construído coletivamente. As incertezas sobre o vírus e a baixa velocidade na imunização da população em países como o Brasil tendem a postergar o retorno "normal" às salas de aulas. Nas cidades brasileiras onde se ensaiou a volta às aulas - mesmo com todos os números da pandemia apontando em outra direção - o que se observou foram professores e estudantes fisicamente mais distantes do que antes da atual crise sanitária. Portanto, é possível que a curto prazo presenciemos, ainda, um modelo de ensino - não apenas de Matemática baseado primordialmente na transmissão de conteúdo. Mas, ainda assim, os coletivos que envolvem o GeoGebra e as TD em geral, têm potencial para nos fazer avançar.

\section{REFERÊNCIAS}

BOGDAN, Roberto C.; BIKLEN, Sari Knopp. Investigação qualitativa em educação. Tradução de Maria João Alvarez, Sara Bahia dos Santos e Telmo Mourinho Baptista. Porto: Porto Editora, 1994.

BORBA, Marcelo de Carvalho; PENTEADO, Miriam Godoy. Pesquisa em Informática e Educação Matemática. Educação em Revista, Belo Horizonte, n. 36, p.239-253, dez. 2002.

BORBA, Marcelo de Carvalho. SILVA, Ricardo Scucuglia. GADANIDIS, George. Fases das tecnologias digitais em Educação Matemática: Sala de Aula e internet em movimento. Belo Horizonte: Autêntica, 2020.

BORBA, Marcelo de Carvalho. VILLARREAL, Mónica E. Humans-with-Media and the Reorganization of Mathematical Thinking: Information and Communication Technologies, Modelling, Experimentation and Visualization. Nova Iorque: Springer, 2005.

BRASIL. Conselho Nacional de Educação. Diretrizes curriculares nacionais para os cursos de matemática, bacharelado e licenciatura. Parecer CNE/CES 1.302/2001, aprovado em 6 de novembro de 2001. Diário Oficial [da] República Federativa do Brasil, seção 1, p. 15, 05 de mar. 2002, Disponível em: http://portal.mec.gov.br/cne/arquivos/pdf/CES13022.pdf. Acesso em: abr. 2020.

BRASIL. Conselho Nacional de Educação. Define as Diretrizes Curriculares Nacionais para a Formação Inicial de Professores para a Educação Básica e institui a Base Nacional Comum 
para a Formação Inicial de Professores da Educação Básica (BNC-Formação). Resolução n. 2/2019, de 20 de dezembro de 2019. Diário Oficial [da] República Federativa do Brasil, seção 1, n. 28, p. 115-119, 10 de fev. de 2020. Disponível em:

http://portal.mec.gov.br/docman/dezembro-2019-pdf/135951-rcp002-19/file. Acesso em: dez. 2020.

CASTRO, Anna Luisa de. GeoGebra, Matemática e o Currículo em Movimento: concepções de um grupo de professores. Anais do XIX Encontro Brasileiro de Estudantes de PósGraduação em Educação Matemática - EBRAPEM. Juiz de Fora-MG, 2015. Disponível em: https://www.ufjf.br/ebrapem2015/files/2015/10/gd6_anna_luisa_castro.pdf. Acesso em: abr. 2021.

COSENZA, Ramon Moreira. GUERRA, Leonor Bezerra. Neurociência e Educação: como o cérebro aprende. Porto Alegre: Artmed, 2011.

FRANCO, Maria Amélia Santoro. Pedagogia da Pesquisa-ação. Educação e Pesquisa, São Paulo, v. 31, n. 3, p. 483-502, set./dez., 2005.

GATTI, Bernardete Angelina. NUNES, Mariana Muniz R. (org.). Formação de professores para $o$ ensino fundamental: estudo de currículos das licenciaturas em pedagogia, língua portuguesa, matemática e ciências biológicas. São Paulo: FCC/DPE, 2009.

HELLMANN, Liliane. et al. GeoGebra no ensino de Cálculo Diferencial e Integral I. R. Eletr. Cient. Inov. Tecnol., Medianeira, v. 2, n. 14, p. 31-46, jul./dez. 2016

LÉVY, Pierre. Cibercultura. Tradução de Carlos Irineu da Costa. $3^{\mathrm{a}}$ ed. São Paulo: Editora 34, 2010.

LIMA, Isabel Bezerra. et al. As contribuições do uso do software GeoGebra para o ensino de Geometria Espacial: uma experiência com discentes de Licenciatura em Matemática. Anais do V Congresso Internacional das Licenciaturas - COINTER PDVL. João Pessoa, PB. 2018. Disponível em: https://cointer.institutoidv.org/inscricao/pdvl/uploadsAnais/ASCONTRIBUI\%C3\% 87\%C3\%95ES-DO-USO-DO-SOFTWARE-GEOGEBRA-PARA-OENSINO-DE-GEOMETRIA-ESPACIAL-uma-experi\%C3\%AAncia-com-discentes-deLicenciatura-em-Matem\%C3\%A1tica-(1).pdf. Acesso em: abr. 2021.

MALCHER JUNIOR, João do Espírito Santo Lima. JUCÁ, Rosineide de Sousa. Práticas docentes relacionadas ao ensino de transformações geométricas. Revista Prática Docente, [S. 1.], v. 4, n. 2, p. 375-390, 2019. Disponível em: https://doi.org/10.23926/RPD.25262149.2019.v4.n2.p375-390.id426. Acesso em: mar. 2021.

MARTINS JÚNIOR, José Cirqueira. Ensino de derivadas em Cálculo I: aprendizagem a partir da visualização com o uso do GeoGebra. Dissertação de Mestrado. Departamento de Matemática. Mestrado Profissional em Educação Matemática. Universidade Federal de Ouro Preto. Ouro Preto, 2015.

MATHIAS, Carlos Eduardo. Um Olhar Humanista sobre os Números Complexos. In: ROQUE, Tatiana; GIRALDO, Victor. (Org.). O Saber do Professor de Matemática Ultrapassando a Dicotomia entre Didática e Conteúdo. 1ed. Rio de Janeiro: Editora Ciência Moderna, 2013, v. 1, p. 107-146. 
MESQUITA, Bruna Rodrigues. Tecnologia de Informação e Comunicação, produção de vídeos didáticos e a formação de professores de matemática nas instituições públicas do Ceará. Trabalho de Conclusão de Curso. Curso de Licenciatura em Matemática, Universidade Estadual Vale do Acaraú (UVA). Sobral, 2020.

PENTEADO, Heloísa Dupas. Pesquisa-ensino: uma modalidade de pesquisa-ação. In: Pesquisa-ensino: a comunicação escolar na formação do professor. PENTEADO, Heloísa Dupas. GARRIDO, Elsa (orgs). São Paulo: Paulinas, 2010.

RICARDO, Jonas da Conceição. SANTOS, Ricardo Marinho dos. Cálculo Vetorial e a Inserção tecnológica: um estudo introdutório com estudantes da graduação em engenharia. Revista Eletrônica Sala de Aula em Foco, ISSN 2316-7297, v. 7, n. 1, p. 29-40, 2018.

SANTAELLA, Lúcia. Culturas e artes do pós-humano: da cultura das mídias à cibercultura. São Paulo. Paulus, 2003.

SIBILIA, Paula. Redes ou Paredes: a escola em tempos de dispersão. Rio de Janeiro: Contraponto, 2012.

TRIPP, David. Pesquisa-ação: uma introdução metodológica. Educação e Pesquisa, São Paulo, v. 31, n. 3, p. 443-466, set./dez., 2005. 